Article

\title{
Investigation of the Mechanical Properties of a Carbon Fibre-Reinforced Nylon Filament for 3D Printing
}

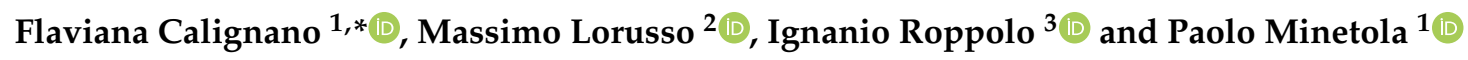 \\ 1 Department of Management and Production Engineering, Politecnico di Torino, Corso Duca degli Abruzzi 24, \\ 10129 Turin, Italy; paolo.minetola@polito.it \\ 2 Istituto Italiano di Tecnologia, Center for Sustainable Future Technologies IIT@Polito, Corso Trento 21, \\ 10129 Turin, Italy; massimo.lorusso@iit.it \\ 3 Department of Applied Science and Technology, Politecnico di Torino, Corso Duca degli Abruzzi 24, \\ 10129 Turin, Italy; ignazio.roppolo@polito.it \\ * Correspondence: flaviana.calignano@polito.it; Tel.: +39-011-090-7218
}

Received: 19 July 2020; Accepted: 2 September 2020; Published: 4 September 2020

\begin{abstract}
Additive manufacturing (i.e., 3D printing) has rapidly developed in recent years. In the recent past, many researchers have highlighted the development of in-house filaments for fused filament fabrication (FFF), which can extend the corresponding field of application. Due to the limited mechanical properties and deficient functionality of printed polymer parts, there is a need to develop printable polymer composites that exhibit high performance. This study analyses the actual mechanical characteristics of parts fabricated with a low-cost printer from a carbon fibre-reinforced nylon filament. The results show that the obtained values differ considerably from the values presented in the datasheets of various filament suppliers. Moreover, the hardness and tensile strength are influenced by the building direction, the infill percentage, and the thermal stresses, whereas the resilience is affected only by the building direction. Furthermore, the relationship between the mechanical properties and the filling factor is not linear.
\end{abstract}

Keywords: additive manufacturing; 3D printing; fused filament fabrication; carbon fibre; mechanical testing

\section{Introduction}

Additive manufacturing (i.e., 3D printing) is constantly evolving due to open source technologies [1-3] and the possibility of producing complex geometries with lower costs, faster production times, and less waste [4-6] than traditionally manufactured parts [7]. Moreover, with the increase in available materials, 3D printing has found applications in the aerospace and architectural industries (e.g., creating complex lightweight and structural models) [8,9], art fields [10,11], and medical fields (e.g., printing tissues and organs) $[12,13]$. However, most plastic 3D printed products are still used primarily as conceptual prototypes rather than functional components because of the poor mechanical and functional properties of the neat polymer used in 3D printing. The development of polymer composites solves these problems [14]. The incorporation of fibre and nanomaterial reinforcements into polymers allows the manufacture of polymer matrix composites, which are characterized by high mechanical performance and excellent functionality $[14,15]$. One process that has been extensively utilized in the fabrication of polymeric 3D printed parts is fused deposition modelling (FDM), which was developed by Stratasys Inc. In 2009, Stratasys's FDM printing patent expired, opening up the market for low-cost FDM 3D printers. For non-Stratasys 3D printers, this process is usually referred to as fused filament fabrication (FFF). In FFF, a thin filament wire is extruded through a heated nozzle (Figure 1). 
The FFF head moves in the $\mathrm{x}$ and $\mathrm{y}$ directions, whereas the platform moves in the $\mathrm{z}$ direction. The part is manufactured by the sequential build-up of these layered depositions, during which each new layer fuses with material that has already been deposited. The final strength, quality, cost and production time of the parts fabricated by FFF are influenced by some process parameters, such as layer thickness, infill pattern, extruder uniformity and/or build-bed temperature, and by the presence of reinforcing materials (e.g., carbon fibres, glass fibres [16]).

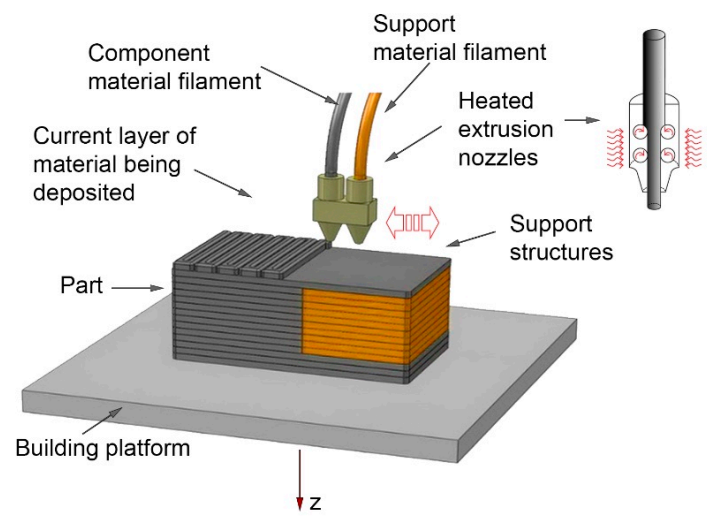

Figure 1. Fused filament fabrication process.

Some researchers have correlated the build orientation (Figure 2b) to the mechanical properties of the part [17-22]. The variations in quality of the melt between adjacent filaments results in a degradation in mechanical properties (tensile strength, compressive strength, flexural strength, hardness, and elastic modulus), especially for parts tested perpendicular to the direction of layer construction. In addition to the orientation of the part on the building platform, the mechanical properties of FFF parts are also significantly influenced by the process parameters of inherent layering (Figure 2a,c), such as the layer thickness, raster angle, raster width, infill pattern and air gap [17,22-25]. Ahn et al. [23] determined that both the air gap and the raster orientation had significant effects on the resulting tensile strength, whereas these factors did not affect the compressive strength. A similar study was carried out by Sood et al. [17] with varying factors of layer thickness, build orientation, raster angle, raster width, and air gap: the tested factors influenced the mesostructural configuration of the built part and the bonding and distortion within the part. Lužanin et al. [26] studied the effects of layer thickness, deposition angle and infill percentage on the maximum flexural force in FFF specimens made of polylactic acid (PLA) and concluded that layer thickness has the maximum effect on the flexural strength followed by the interaction between the deposition angle and the infill percentage. Despite its advantages over conventional manufacturing processes, FFF parts often exhibit low mechanical properties. One of the possible methods to improve the strength of FFF parts is adding reinforcing materials, such as carbon fibres, into pure thermoplastic matrix materials to form carbon fibre-reinforced thermoplastic composites [27-29]. Several studies have been conducted related to FFF and carbon fibre (CF) composites. A list of various studies of FFF with chopped fibre-reinforced thermoplastics is given in Table 1.

(a)

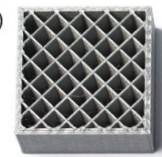

$20 \%$

(c)

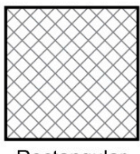

Rectangular

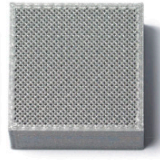

$50 \%$

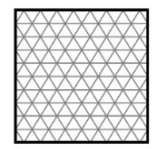

Triangular or

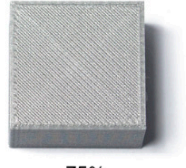

$75 \%$

(b)

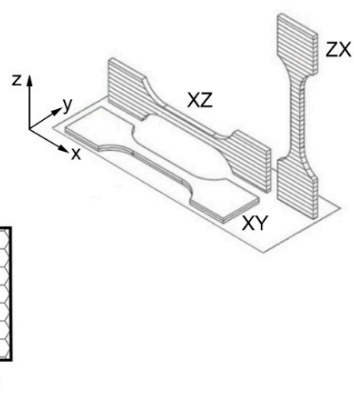

Figure 2. Examples of (a) infill percentage, (b) build orientation and (c) infill pattern. 
Table 1. A summary of some studies on FFF with chopped fibres.

\begin{tabular}{|c|c|c|c|c|}
\hline Reinforcement & Matrix Material & Investigated Properties & Limitations & References \\
\hline Carbon fibres & ABS & $\begin{array}{l}\text { Tensile strength } \\
\text { and tensile modulus }\end{array}$ & $\begin{array}{l}\text { Porosity, weak interfacial } \\
\text { adhesion between the fibres } \\
\text { and the matrix } \\
\text { and fibre breakage }\end{array}$ & [27] \\
\hline $\begin{array}{l}\text { Vapour-grown } \\
\text { carbon fibres }\end{array}$ & ABS & $\begin{array}{c}\text { Tensile strength } \\
\text { and tensile modulus }\end{array}$ & $\begin{array}{l}\text { Interlayer fusion, intralayer } \\
\text { fusion, and a change from } \\
\text { ductile to brittle behaviour }\end{array}$ & [28] \\
\hline Carbon fibres & ABS & $\begin{array}{l}\text { Strength, stiffness, thermal } \\
\text { properties, distortion, } \\
\text { and geometric tolerances }\end{array}$ & & {$[30]$} \\
\hline Carbon fibres & ABS & $\begin{array}{l}\text { Tensile strength, } \\
\text { Young's modulus, } \\
\text { and flexural properties }\end{array}$ & $\begin{array}{c}\text { Decreases in toughness, } \\
\text { yield strength and ductility } \\
\text { and increases in porosity with } \\
\text { increased carbon fibre content }\end{array}$ & [31] \\
\hline Carbon fibres & PLA & $\begin{array}{c}\text { Tensile strength } \\
\text { and tensile modulus }\end{array}$ & & [32] \\
\hline Carbon fibres & PLA & Fracture properties & $\begin{array}{l}\text { Critical factors for the fracture } \\
\text { toughness: bead layup } \\
\text { sequence, fiber pullout, } \\
\text { interfacial de-bonding, } \\
\text { and void formation }\end{array}$ & [33] \\
\hline Carbon fibres & PLA & Tensile strength & $\begin{array}{c}\text { Tensile strength increases with } \\
\text { infill density and low layer } \\
\text { thickness }\end{array}$ & [34] \\
\hline Carbon fibres & Nylon & Charpy impact testing & $\begin{array}{l}\text { Toughness results show a severe } \\
\text { anisotropy in toughness } \\
\text { and high dependence on } \\
\text { the infill strategy }\end{array}$ & {$[35]$} \\
\hline
\end{tabular}

Love et al. [30] showed that filaments made from CFs and acrylonitrile butadiene styrene (ABS) polymer significantly increase the strength and stiffness of the final parts: the tensile strength and stiffness of the composite sample were $70.69 \mathrm{MPa}$ and $8.91 \mathrm{GPa}$, respectively, whereas these values for the pure ABS sample were $29.31 \mathrm{MPa}$ and $2.05 \mathrm{GPa}$, respectively. They also demonstrated that the addition of CFs decreased the distortion of the printed ABS/CF, which was attributed to the $124 \%$ increase in thermal conductivity compared to unfilled ABS. Ning et al. [31] investigated the material properties of ABS polymer matrices with different CF contents. They concluded that compared with pure ABS specimens, adding CFS into ABS could increase the tensile strength and Young's modulus but may decrease the toughness, yield strength and ductility. Porosity became the most severe in the specimens with a $10 \mathrm{wt} \%$ carbon fibre content. Ivey et al. [32] analysed specimens produced using a commercial polylactic acid (PLA) filament and a PLA filament reinforced with short-carbon fibres (PLA/CF). The tensile properties of the PLA and PLA/CF filaments showed that the addition of carbon fibres to the PLA filament led to a significant increase in the elastic modulus of the FFF samples. The fracture properties (stress intensity factor and energy release rate) of PLA and its short CF reinforced composites have been studied by Papon and Haque [33]. Different CF concentrations were printed with two bead lay-up orientations using PLA and CF/PLA composite filaments. The most critical factors for the fracture toughness seem to be the bead layup sequence, fiber pullout, interfacial de-bonding, and void formation. Higher fiber contents did not show improvement in fracture toughness due to higher intra-bead voids, microcracks, and poor interfacial bonding. Yasa [35] pointed out that the build orientation has a significant influence of carbon-reinforced tough nylon. The impact toughness of specimens built vertically was reduced by $90 \%$ in comparison to other directions where the impact was not received in between deposited layers. In 2014, MarkForged $(C)$ developed the first continuous carbon fibre composite 3D printer. Printed samples generated with MarkForged $\subseteq$ printers have been characterized in previous studies [36-39]. A summary of some studies focused on the FFF of 
continuous fibre-reinforced polymers is given in Table 2. These studies observed some discontinuities in the construction of samples: the carbon fibres were not completely continuous. Experiments showed that discontinuities in the fibres led to premature failure in areas where the fibres were absent, severely reducing the tensile strength of the sample.

Table 2. A summary of some studies on FFF with continuous fibres.

\begin{tabular}{ccccc}
\hline Reinforcement & Matrix Material & $\begin{array}{c}\text { Investigated } \\
\text { Properties }\end{array}$ & Limitations & References \\
\hline Carbon fibres & Nylon & Tensile properties & $\begin{array}{c}\text { Discontinuities of } \\
\text { the fibres and porosity }\end{array}$ & [36] \\
\hline $\begin{array}{c}\text { Carbon, glass } \\
\text { and Kevlar fibres }\end{array}$ & Nylon & Tensile properties & $\begin{array}{c}\text { Poor bonding } \\
\text { and porosity }\end{array}$ & [37] \\
\hline $\begin{array}{c}\text { Carbon, glass } \\
\text { and Kevlar fibres }\end{array}$ & Nylon & $\begin{array}{c}\text { Tensile and flexural } \\
\text { properties }\end{array}$ & $\begin{array}{c}\text { Weak bonding } \\
\text { and porosity }\end{array}$ & [38] \\
\hline Carbon fibres & PLA & $\begin{array}{c}\text { Flexural strength } \\
\text { and modulus }\end{array}$ & None reported & [39] \\
\hline
\end{tabular}

This study investigated the performance of parts produced with an FFF 3D printer from chopped carbon fibre-reinforced nylon filaments (nylon-carbon). This filament is composed of nylon 612 with 20\% carbon fibres. Nylon 612 (Polyamide 612) gives high resistance to the filament (high impact strength; good resistance to greases, oils, fuels, hydraulic fluids, water, alkalis and saline; good stress cracking resistance; low coefficients of sliding friction; high abrasion resistance; and high tensile and flexural strength [40]), a relatively low water absorption and a high dimensional stability. The CFs add stability and rigidity, which makes the parts less likely to warp than standard nylon. Due to these characteristics, this filament is ideal for engineering parts, custom end-use production parts, functional prototyping and testing, structural parts, jigs, fixtures, and other tooling. Although the extrusion of preimpregnated fibres does not allow changes in the fibre volume fraction, this approach eliminates the problems associated with poor fibre/matrix interfaces if the impregnation is good and if adequate process parameters are selected. However, the high values of mechanical properties (e.g., tensile modulus of 500-8000 MPa, tensile strength of 54-110 MPa, and hardness of $110 \mathrm{MPa}$ ) found in the material datasheets from various manufacturers do not specify the construction conditions, i.e., orientation and filling. This is because some data is obtained by building specimens with other technologies, such as injection molding. In the last year alone, filament manufacturers have been trying to provide mechanical test data by making the specimens using FFF technology. Therefore, the purpose of this study is to analyse the actual mechanical characteristics of a nylon-carbon filament using a low-cost printer.

\section{Materials and Methods}

\subsection{Fabrication of Samples}

In this study, a nylon-carbon filament produced by Fiber Force Italy [41], which had a standard diameter of $1.75 \mathrm{~mm}$, was used for 3D printing. The nylon-carbon filament is composed of nylon 612 with $20 \%$ carbon fibres (chopped fibres with a random orientation). Each fibre is approximately $10 \mu \mathrm{m}$ in diameter and $30 \mu \mathrm{m}$ in length. A Sharebot Next Generation printer with a $0.4 \mathrm{~mm}$ nozzle was used to print tensile and Charpy impact test specimens with a layer thickness of $0.20 \mathrm{~mm}$ and three different values of infill, 15\%,80\%, and 100\%, in two different planes, XY and XZ (Figure 3). Many of the samples produced on the ZX plane showed defects during construction due to problems regarding adhesion on the building platform. For this reason, these samples were not analysed. Choosing an infill pattern depends on the kind of model, the desired structural strength, and the print speed. In general, rectilinear, linear and honeycomb infill patterns are preferred. From a study conducted by Akhoundi and Behravesh [42], honeycomb was found to be the least favourable pattern at a filling 
percentage of 100, whereas it provided better properties at a low filling percentage. The honeycomb pattern is more susceptible to creating small voids in the matrix, leading to a significant reduction in the specific tensile strength [42]. Therefore, filling with $15 \%$ of the material was realized with a honeycomb structure. The first four layers and the last four layers that enclose the part are filled with a solid layer. Linear filling was used for the samples with filling percentages of $80 \%$ and $100 \%$. Table 3 shows the parameters of the 3D printing process.
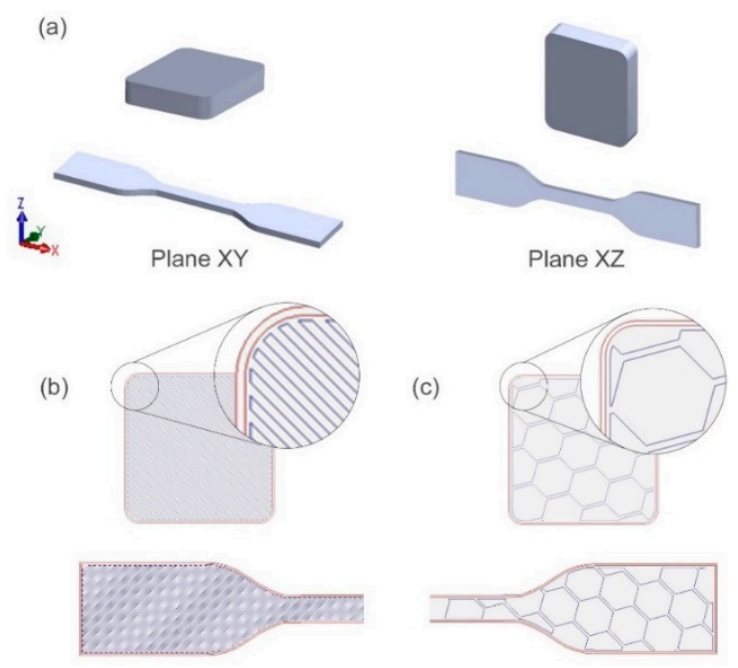

Figure 3. (a) Sample building direction, (b) linear filling at $100 \%$, and (c) honeycomb filling at $15 \%$.

Table 3. 3D printing process parameters.

\begin{tabular}{ccc}
\hline 3D Printer & Filament & Value \\
\hline & Diameter & $1.75 \mathrm{~mm}$ \\
Exarebot Next Generation & $230^{\circ} \mathrm{C}$ \\
& Bed temperature & $40{ }^{\circ} \mathrm{C}$ \\
& Perimeter print speed & $35 \mathrm{~mm} / \mathrm{s}$ \\
& Infill and support print speed & $40 \mathrm{~mm} / \mathrm{s}$ \\
& Layer height & $0.20 \mathrm{~mm}$ \\
\hline
\end{tabular}

\subsection{Mechanical Testing}

The mechanical properties relevant for the sports, automotive and aerospace industries, such as the hardness, tensile and resilience of 3D printed nylon-carbon specimens, are evaluated via mechanical testing.

During the Brinell hardness test (ISO 2039-1, DIN 53456), an indenter comprising a hardened steel ball (diameter: $5 \mathrm{~mm}$ ) is pressed into the top surface of the sample for a standard length of time (30 s) under a standard load of $49 \mathrm{~N}$ [43]. After removing the load, the circular indentation is then measured in two mutually perpendicular directions, taking the average of the two readings. The hardness $\mathrm{H}\left[\mathrm{N} / \mathrm{mm}^{2}\right]$ is the ratio between the applied load and the surface area of the impression.

Tensile tests were conducted in accordance with ASTM D638 using an Instron 3366 dynamometer, which was equipped with a $10 \mathrm{kN}$ load cell, at a strain rate of $10 \mathrm{~mm} / \mathrm{min}$. Five specimens for each set were tested, and the final results were obtained by averaging the data.

Charpy impact tests were performed with a Charpy Zwick Roell B513E to study the energy absorption of the different samples. The test was carried out in accordance with ISO179-1, and the unnotched specimen dimensions were $80 \times 10 \times 4 \mathrm{~mm}$. The distance between the supports was $40 \mathrm{~mm}$. Five samples for each set were tested. After the test, each sample was inspected, and the fracture surface was photographed. 


\section{Results and Discussion}

\subsection{Hardness and Tensile Properties}

In Table 4, the hardness values are reported. The results showed that the samples produced in the XY plane have a higher hardness than the samples produced in the XZ plane. This discrepancy is evident for the samples with 100\% filling, whereas for the other samples with 15\% and $80 \%$ filling, the effect is not as clear. The samples built in the XZ plane with $80 \%$ and $100 \%$ filling have similar hardness. Increasing the filling percentage results in an increase in the hardness in the XY plane but also increases material costs and lengthens production times.

Table 4. Hardness values in $\mathrm{N} / \mathrm{mm}^{2}$.

\begin{tabular}{|c|c|c|c|c|c|c|}
\hline \multirow{2}{*}{ Number Indentation } & \multicolumn{6}{|c|}{ Filling Percentage and Building Direction } \\
\hline & $15 \%, X Y$ & $15 \%, X Z$ & $80 \%, X Y$ & $80 \%, X Z$ & $100 \%, X Y$ & $100 \%, X Z$ \\
\hline 1 & 14.4 & 10.1 & 55.6 & 48.5 & 80.1 & 51.1 \\
\hline 2 & 10.3 & 9.2 & 54.7 & 49.3 & 80.9 & 45.4 \\
\hline 3 & 13.0 & 11.5 & 53.5 & 52.2 & 78.3 & 52.2 \\
\hline 4 & 10.3 & 13.0 & 48.2 & 53.7 & 75.3 & 41.3 \\
\hline 5 & 8.5 & 10.0 & 55.9 & 45 & 81.9 & 43.4 \\
\hline Average & 11.3 & 10.8 & 53.6 & 49.7 & 79.3 & 46.7 \\
\hline Std. dev. & 2.4 & 1.5 & 3.1 & 3.4 & 2.6 & 4.8 \\
\hline
\end{tabular}

In Table 5 and Figure 4, the results from the tensile tests are reported. The results show that, in general, the specimens built in the $X Z$ direction are stiffer than those built in the XY direction; the former exhibit higher Young's modulus and higher stress at break. In contrast, the energy at break is higher for the samples built in the XY direction.

Table 5. Tensile test results for the specimens printed on a Sharebot printer from a $1.75 \mathrm{~mm}$ filament.

\begin{tabular}{lcccccc}
\hline Sample & Young's Modulus E [MPa] & $\sigma_{\mathbf{Y}}[\mathrm{MPa}]$ & $\boldsymbol{\sigma}_{\text {UTS }}[\mathrm{MPa}]$ & $\boldsymbol{\sigma}_{\text {break }}[\mathrm{MPa}]$ & Elongation at Break [\%] & Energy at Break [m]] \\
\hline $15 \%, \mathrm{XY}$ & $930 \pm 77$ & $17 \pm 0.3$ & $22 \pm 0.7$ & $21 \pm 0.7$ & $2.0 \pm 0.2$ & $202 \pm 50$ \\
$15 \%, \mathrm{XZ}$ & $1467 \pm 21$ & $26 \pm 0.8$ & $31 \pm 0.6$ & $25 \pm 0.6$ & $1.5 \pm 0.1$ & $76 \pm 15$ \\
$80 \%, \mathrm{XY}$ & $1552 \pm 60$ & $35 \pm 0.4$ & $44 \pm 1.2$ & $37 \pm 1.2$ & $2.2 \pm 0.1$ & $625 \pm 194$ \\
$80 \%, \mathrm{XZ}$ & $2294 \pm 154$ & $36 \pm 1.8$ & $57 \pm 4.1$ & $44 \pm 4.1$ & $2.6 \pm 0.5$ & $361 \pm 119$ \\
$100 \%, \mathrm{XY}$ & $1625 \pm 64$ & $39 \pm 1.4$ & $45 \pm 1.9$ & $38 \pm 1.9$ & $2.0 \pm 0.1$ & $464 \pm 209$ \\
$100 \%, \mathrm{XZ}$ & $2403 \pm 95$ & $42 \pm 1.7$ & $56 \pm 3.9$ & $45 \pm 3.9$ & $2.8 \pm 1.0$ & $163 \pm 89$ \\
\hline
\end{tabular}

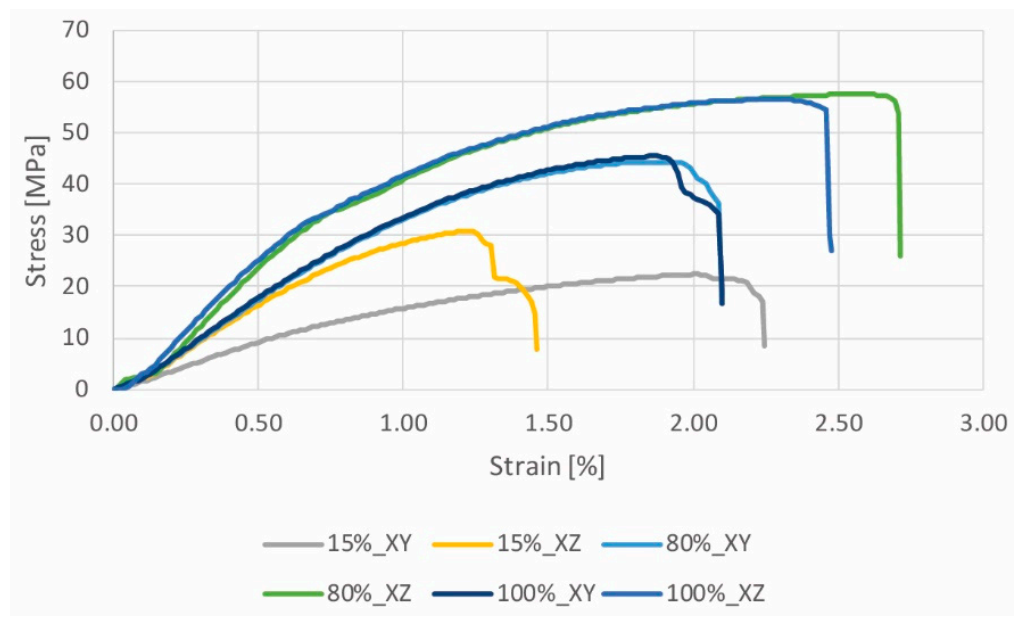

Figure 4. Stress-strain curves. 
As previously reported by Rodriguez et al. [44], this means that building in the XZ direction leads to stiffer and more fragile components, whereas when an object is built in the XY direction, the object is softer but more resistant to failure.

Regarding the filling factor, as the filling percentage increases, the specimen stiffness increases. The choice of the type of infill pattern can influence the behaviour of the material, leading to a nonlinear relationship between the mechanical properties and the filling factor. For instance, the Young's modulus of the samples with a filling factor of $15 \%$ (honeycomb infill pattern) is approximately $60 \%$ of the average Young's modulus of the specimens with a filling factor of $100 \%$ (linear infill pattern), independent of the building direction. The modulus values with a filling factor of $80 \%$ (linear infill pattern) increase by up to $95 \%$. A similar trend could be evidenced for the tensile strength at break $\sigma_{\text {break }}(53 \%$ for a $15 \%$ filling factor and $97 \%$ for an $80 \%$ filling factor). This finding means that once the stiffness requirements for a component are established, important weight reductions could be implemented by using only the amount of material sufficient to satisfy the criteria and the most suitable infill pattern. On the other hand, the use of an exceeding amount of material could be even detrimental: the more material there is, the more defects generated during the printing process, leading to a decrease in the mechanical properties. Although $100 \%$ fill density can provide maximum strength, it can negatively affect the overall cost by increasing the print time and the amount of material consumed. For certain applications, it is not necessary to use a fill density of $100 \%$ due to the nature of the application itself, for example in the case of components not subjected to loads or stresses of certain amounts. Therefore, determining the required fill density based on the nature and application of the product would be very important for large-scale production lines to optimize resources. Obviously, the load capacity of the printed parts is a function of the filling density, the fraction of the volume of the fiber to the matrix and the quality of the chemical and mechanical bond between droplets/layers. Low fill densities can lead to an increase in gaps within the structure (i.e., an increase in porosity) and this can cause the strength of the part to decrease [45]. A filling percentage of $100 \%$ can cause raster overlap or a negative air gap size, which, in turn, negatively influences the strength of the material.

Regarding the mechanical properties in the $X Z$ orientation, a filling percentage of $80 \%$ improves the material characteristics, among which the hardness slightly increases and the energy at break increases more substantially. In the XY orientation, the difference between the samples produced with the $15 \%$ honeycomb strategy and those produced with higher filling percentages (linear filling) is more consistent in terms of hardness than stiffness. This finding confirms that the combination of filling percentage and filling strategy has a high effect on the mechanical properties. Fernández-Vicente et al. [46] carried out a study that analysed the influence of the pattern and infill percentage: the density of the infill was a decisive factor in tensile strength, and the combination of a rectilinear pattern and a $100 \%$ filling percentage provided the greatest tensile strength. This result was not fully found in the present case. Samples with $80 \%$ and $100 \%$ filling percentages exhibited similar values for the Young's modulus and stress at break with differences of $4 \%$ and $5 \%$ in the $X Y$ and $X Z$ planes, respectively. The greatest deviation is observed for energy at break: samples with $80 \%$ filling exhibited higher values $(+35 \%$ and $+121 \%$ in the XY and XZ planes, respectively) than those built with $100 \%$ filling. This finding can be explained by considering the following factors: thermal stresses during construction, random orientation of the fibres and filling percentage. Residual stresses induced in the layer-by-layer fabrication process of additive manufactured parts have a significant impact on their mechanical properties and dimensional accuracy [23,47]. Based on the coefficient of thermal expansion (CTE), the material is prone to shrinkage, which induces internal stresses due to the evolving material stiffness upon solidification and the bonds between the beads constraining the material. A fraction of these stresses is released due to viscoelastic relaxation and material deformations. During cooling, the crystallization reaction introduced additional strains that promote internal stresses and partial deformations. The combined behaviour of these factors simultaneously influences the mechanical properties. The random orientation of the fibres affects the thermal properties in different directions. Therefore, the fibres significantly increase the conductivity in the bead direction and other directions. 
The thermal conductivity of the carbon fibres helps the already cooled bottom beads soften again after a hot bead is deposited on their upper surfaces, leading to improved packing and smaller gaps. This assertion would explain the smaller gap between the results for hardness and stiffness in the XZ plane for the two infill percentages of $80 \%$ and $100 \%$. In the XY direction, the heating of the plate and the lower number of layers reduces the thermal stress, making the effect of the filling more obvious, thereby highlighting a greater difference in hardness between $80 \%$ and $100 \%$ infills and a lesser difference in the Young's modulus and stress at break. A 20\% reduction in the infill percentage (from $100 \%$ to $80 \%$ ) led to greater energy at break in both construction directions.

A comparison of the obtained values with those found in the material datasheets from the supplier and other manufacturers is shown in Table 6. The FFF samples exhibited higher mechanical property values than pure thermoplastic material (nylon) $[48,49]$ but lower mechanical property values than the injection moulded samples [50]. Comparing the values reported for Nylon 12CF [48] with those obtained in this study with the same percentage of filling, it can be observed that the increase in carbon fibres from $20 \%$ (nylon-carbon) to $35 \%$ (Nylon 12CF) with the same construction orientation allows an increase in the tensile properties. Considering instead a reduction of 5\% (CF112) [51] of the percentage of carbon fiber, the mechanical properties are reduced except the elongation at break considering what is declared by the manufacturer. The percentages and type of filling and orientation of the samples are not indicated. The values reported by the Fiber Force manufacturer show a certain difference compared to what was found in this study. The datasheet does not show the data relating to the type of infill used. The other process parameters used are the same as in this study. This therefore focuses on the fact that with the same filament and process parameters, the results determined with a tensile test are also conditioned by the geometry of the tested specimen. The ISO 527-1/-2 and ASTM D638 (used in the scientific literature) standards define test methods for tensile tests. Although technically equivalent, the tests carried out according to these standards do not provide fully comparable results, as the shape of the specimens, the test speed, and the determination of the results are different from each other in several respects $[52,53]$.

Table 6. Comparison of the tensile test results.

\begin{tabular}{|c|c|c|c|c|c|}
\hline Manufacturer Data & Young's Modulus E [MPa] & $\sigma_{\mathrm{y}}[\mathrm{MPa}]$ & $\sigma_{\text {break }}[\mathrm{MPa}]$ & $\begin{array}{c}\text { Elongation at } \\
\text { Break [\%] }\end{array}$ & $\begin{array}{l}\text { Energy at } \\
\text { Break }[\mathrm{J}]\end{array}$ \\
\hline Injection moulded-Nylon Carbon & 6000 & 100 & - & - & - \\
\hline Nylon Carbon (Fiber Force) & $\begin{array}{c}1844 \\
(15 \%, \mathrm{XY}) \\
2758 \\
(100 \%, \mathrm{XY})\end{array}$ & - & $\begin{array}{c}33.7 \\
(15 \%, \mathrm{XY}) \\
66.3 \\
(100 \%, \mathrm{XY})\end{array}$ & $\begin{array}{c}5.7 \\
(15 \%, \mathrm{XY}) \\
6.7 \\
(100 \%, \mathrm{XY})\end{array}$ & $\begin{array}{c}5.45 \\
(15 \%, \mathrm{XY}) \\
12.2 \\
(100 \%, \mathrm{XY})\end{array}$ \\
\hline CF112 (Fillamentum) & 2200 & 52.4 & 37.7 & 8 & - \\
\hline Nylon (Stratasys) & $\begin{array}{c}1282 \\
(100 \%, \mathrm{XZ})\end{array}$ & $\begin{array}{c}32 \\
(100 \%, \mathrm{XZ})\end{array}$ & $\begin{array}{c}46 \\
(100 \%, X Z)\end{array}$ & $\begin{array}{c}3.0 \\
(100 \%, X Z)\end{array}$ & - \\
\hline Nylon (Fiber Force) & $\begin{array}{c}881.9 \\
(15 \%, \mathrm{XY}) \\
1529.0 \\
(100 \%, \mathrm{XY})\end{array}$ & - & $\begin{array}{c}20.7 \\
(15 \%, \mathrm{XY}) \\
41.1 \\
(100 \%, \mathrm{XY})\end{array}$ & $\begin{array}{c}13.94 \\
(15 \%, \mathrm{XY}) \\
31.30 \\
(100 \%, \mathrm{XY})\end{array}$ & $\begin{array}{c}10.48 \\
(15 \%, \mathrm{XY}) \\
49.70 \\
(100 \%, \mathrm{XY})\end{array}$ \\
\hline
\end{tabular}

\subsection{Resilience}

Figure 5 shows the test results for the specimens built on the XY plane and the XZ plane for each filling ratio. In general, the samples constructed on the $X Y$ plane have a resilience that is approximately 4.6 times, 3.1 times, and 2.9 times that of the samples built on the XZ plane with filling factors of $15 \%$, $80 \%$, and $100 \%$, respectively. 


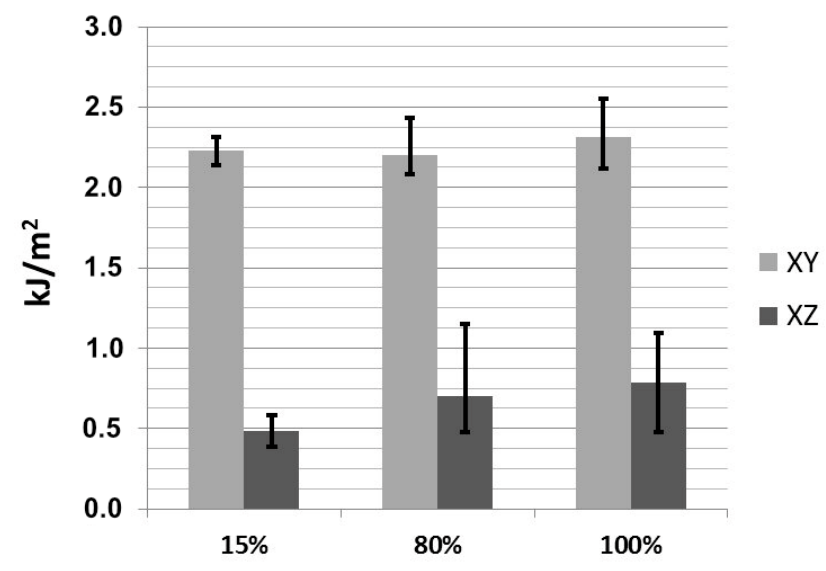

Figure 5. Charpy impact test results.

The filling factor does not have a strong influence on the resilience. The resilience of samples manufactured in the XY plane with a filling percentage of $100 \%$ is only $4 \%$ higher than the resilience of samples built on the same plane with a filling percentage of $15 \%$. The resilience of samples built on the XZ plane with a filling percentage of $100 \%$ is $29 \%$ higher than that of samples with a filling percentage of $15 \%$. It is evident that the effect of the building direction is more important than the influence of the filling factor. This finding indicates that if the layers are parallel to the mechanical test direction, the mechanical properties are lower than in the sample where the layers are perpendicular to the mechanical test direction.

Figure 6a shows that the fracture surface of the samples built on the $\mathrm{XZ}$ plane corresponds to the interlayer part. During the test, two samples constructed on the $X Y$ plane with a filling percentage of $15 \%$ were not broken: the last four layers were bent (Figure $6 b, c$ ), and the samples passed through the supports. The samples that did not break during the test were not considered in the evaluation of resilience.

(a)
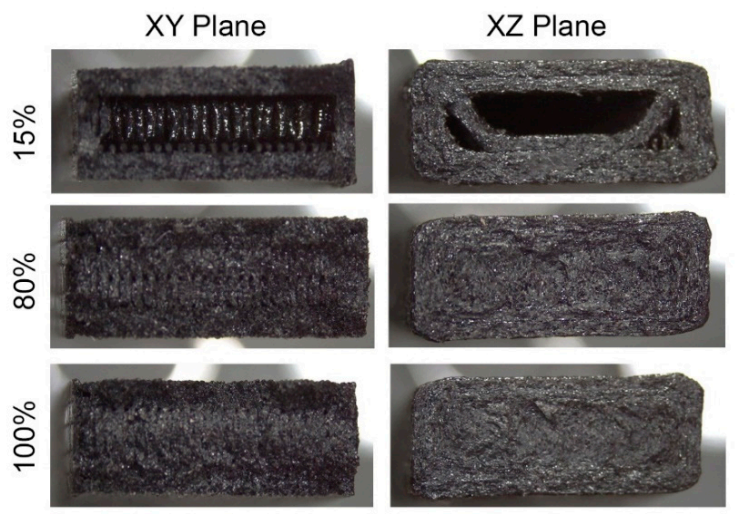

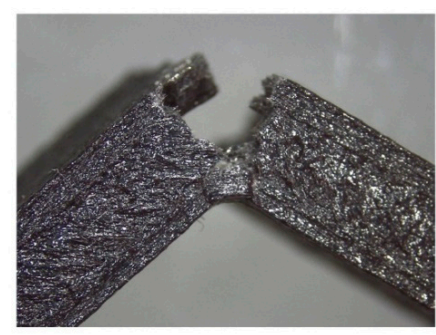

(b)

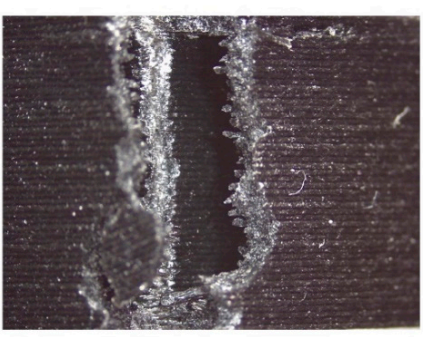

(c)

Figure 6. (a) Fracture surfaces from the Charpy impact test samples: (b) side view and (c) top view of the sample built on the XY plane with a filling percentage of $15 \%$ that has not been broken. 
From the images of the fracture section (Figure 6), it is possible to observe greater compactness between the first and last layer and filling of samples in the $\mathrm{XZ}$ plane at $80 \%$ and $100 \%$ with respect to the XY plane. This may be due to the very principle of the additive process. Additive processes develop in layers. If it considers, for example, the specimen for Charpy tests, the number of layers varies from 20 layers for the $X Y$ plane to 50 layers for the one built in the $X Z$ plane. Therefore, considering that the first and last 4 layers are solid, the specimen constructed on the XY plane will have $2.4 \mathrm{~mm}$ of infill at $15 \%, 80 \%$ or $100 \%$ and $1.6 \mathrm{~mm}(0.8 \mathrm{~mm}$ in the first 4 layers and $0.8 \mathrm{~mm}$ in the last 4 layers) of $100 \%$ filling; while the one built on the $\mathrm{XZ}$ plane will have $8.4 \mathrm{~mm}$ of filling at $15 \%, 80 \%$ or $100 \%$ and always $1.6 \mathrm{~mm}$ of full. Therefore, in the case of hardness and resilience, the components in the XY plane have higher values than those in the $\mathrm{XZ}$ plane having a reduced number of layers which reduces the percentage of defects. In the case of tensile test, on the other hand, the specimen has a thin section in the useful area that reverses the condition, i.e., it has more layers but with a reduced filling value, also considering the effects in the contour that decrease the percentage of votes in the transition area between outline and fill. The contours scanned around the part to be filled in every layer limited these porosities. Due to the fact that the specimens were quite thin, the effect of dense contours probably contributes to a higher Young's modulus [54].

\section{Conclusions}

Although short fibre-reinforced composites offer better mechanical performance than their unreinforced counterparts, there is still a certain gap between the mechanical properties of preimpregnated fibre and conventionally manufactured fibre-reinforced polymer composites. Furthermore, the weight percentage of the carbon fibres and the selected process parameters can greatly influence the mechanical characteristics, as reported in the literature.

Based on the experimental results of this study, the following conclusions may be drawn:

- The samples produced in the XY plane have higher hardness than the samples built in the XZ plane. The samples built in the XZ plane with $80 \%$ and $100 \%$ filling have similar hardness values. At a filling percentage of $100 \%$, the samples built in the $X Z$ plane exhibit much lower hardness than those constructed in the $X Y$ plane.

- The specimens built in the $X Z$ direction are stiffer than those built in the XY direction, in which the former exhibits higher Young's modulus and higher stress at break. In contrast, the energy at break is higher for the samples built in the XY direction. Furthermore, the relationship between the mechanical properties and filling factor is not linear.

- The ISO 527-1/-2 and ASTM D638 standards, although technically equivalent, do not provide fully comparable results

- The filling factor does not have a strong influence on the resilience on the XY plane.

Author Contributions: Conceptualization, F.C.; methodology, F.C.; validation, F.C., M.L., and I.R.; formal analysis, F.C., M.L., and I.R.; investigation, F.C., M.L., and I.R.; writing-Original draft preparation, F.C., M.L., I.R., and P.M. All authors have read and agreed to the published version of the manuscript.

Funding: This research received no external funding.

Acknowledgments: The authors gratefully acknowledge Arturo Donghi of Sharebot Company for having supplied the FFF printer and the $1.75 \mathrm{~mm}$ nylon-carbon filament for printing the test specimens.

Conflicts of Interest: The authors declare no conflict of interest.

\section{References}

1. Kostakis, V.; Niaros, V.; Giotitsas, C. Open source 3D printing as a means of learning: An educational experiment in two high schools in Greece. Telemat. Inform. 2015, 32, 118-128. [CrossRef]

2. Rayna, T.; Striukova, L.; Darlington, J. Co-creation and user innovation: The role of online 3D printing platforms. J. Eng. Technol. Manag. 2015, 37, 90-102. [CrossRef] 
3. West, J.; Kuk, G. The complementarity of openness: How MakerBot leveraged Thingiverse in 3D printing. Technol. Forecast. Soc. Change 2016, 102, 169-181. [CrossRef]

4. Boschetto, A.; Bottini, L. Design for manufacturing of surfaces to improve accuracy in Fused Deposition Modeling. Robot. Comput. Integr. Manuf. 2016, 37, 103-114. [CrossRef]

5. Yang, S.; Tang, Y.; Zhao, Y.F. A new part consolidation method to embrace the design freedom of additive manufacturing. J. Manuf. Process. 2015, 20, 444-449. [CrossRef]

6. Domingo-Espin, M.; Puigoriol-Forcada, J.M.; Garcia-Granada, A.A.; Llumà, J.; Borros, S.; Reyes, G. Mechanical property characterization and simulation of fused deposition modeling Polycarbonate parts. Mater. Des. 2015, 83, 670-677. [CrossRef]

7. Baumers, M.; Dickens, P.; Tuck, C.; Hague, R. The cost of additive manufacturing: Machine productivity, economies of scale and technology-push. Technol. Forecast. Soc. Change 2016, 102, 193-201. [CrossRef]

8. Kroll, E.; Artzi, D. Enhancing aerospace engineering students' learning with 3D printing wind-tunnel models. Rapid Prototyp. J. 2011, 17, 393-402. [CrossRef]

9. Wong, K.V.; Hernandez, A. A Review of Additive Manufacturing. ISRN Mech. Eng. 2012, 2019, 7-31. [CrossRef]

10. Short, D.B. Use of 3D printing by museums: Educational exhibits, artifact education, and artifact restoration. 3D Print. Addit. Manuf. 2015, 2, 209-215. [CrossRef]

11. Walters, P.; Davies, K. 3D Printing for Artists: Research and Creative Practice. Rapport 2010, 1, $12-15$.

12. Murphy, S.V.; Atala, A. 3D bioprinting of tissues and organs. Nat. Biotechnol. 2014, 32, 773-785. [CrossRef] [PubMed]

13. Chen, H.; Yang, X.; Chen, L.; Wang, Y.; Sun, Y. Application of FDM three-dimensional printing technology in the digital manufacture of custom edentulous mandible trays. Sci. Rep. 2016, 6, 19207. [CrossRef] [PubMed]

14. Wang, X.; Jiang, M.; Zhou, Z.; Gou, J.; Hui, D. 3D printing of polymer matrix composites: A review and prospective. Compos. Part B Eng. 2017, 110, 442-458. [CrossRef]

15. Mohammadizadeh, M.; Fidan, I.; Allen, M.; Imeri, A. Creep behavior analysis of additively manufactured fiber-reinforced components. Int. J. Adv. Manuf. Technol. 2018, 99, 1225-1234. [CrossRef]

16. Mohan, N.; Senthil, P.; Vinodh, S.; Jayanth, N. A review on composite materials and process parameters optimisation for the fused deposition modelling process. Virtual Phys. Prototyp. 2017, 12, 47-59. [CrossRef]

17. Sood, A.K.; Ohdar, R.K.; Mahapatra, S.S. Parametric appraisal of mechanical property of fused deposition modelling processed parts. Mater. Des. 2010, 31, 287-295. [CrossRef]

18. Bagsik, A.; Schöppner, V.; Klemp, E. FDM Part Quality Manufactured with Ultem*9085. In Proceedings of the 14th International Scientific Conference on Polymeric Materials, Halle, Germany, 15-17 September 2010; N.M.Emanuel Institute of Biochemical Physics, Russian Academy of Sciences: Moscow, Russia, 2010.

19. Torrado Perez, A.R.; Roberson, D.A.; Wicker, R.B. Fracture surface analysis of 3D-printed tensile specimens of novel ABS-based materials. J. Fail. Anal. Prev. 2014, 14, 343-353. [CrossRef]

20. Ziemian, C.; Sharma, M.; Ziemian, S. Anisotropic Mechanical Properties of ABS Parts Fabricated by Fused Deposition Modelling. In Mechanical Engineering; Intech Open: London, UK, 2012.

21. Zaldivar, R.J.; Witkin, D.B.; McLouth, T.; Patel, D.N.; Schmitt, K.; Nokes, J.P. Influence of processing and orientation print effects on the mechanical and thermal behavior of 3D-Printed ULTEM@9085 Material. Addit. Manuf. 2017, 13, 71-80. [CrossRef]

22. Mohamed, O.A.; Masood, S.H.; Bhowmik, J.L. Experimental Investigations of Process Parameters Influence on Rheological Behavior and Dynamic Mechanical Properties of FDM Manufactured Parts. Mater. Manuf. Process. 2016, 15, 1983-1994. [CrossRef]

23. Ahn, S.H.; Montero, M.; Odell, D.; Roundy, S.; Wright, P.K. Anisotropic material properties of fused deposition modeling ABS. Rapid Prototyp. J. 2002, 8, 248-257. [CrossRef]

24. Wu, W.; Geng, P.; Li, G.; Zhao, D.; Zhang, H.; Zhao, J. Influence of layer thickness and raster angle on the mechanical properties of 3D-printed PEEK and a comparative mechanical study between PEEK and ABS. Materials 2015, 8, 5834-5846. [CrossRef] [PubMed]

25. Tymrak, B.M.; Kreiger, M.; Pearce, J.M. Mechanical properties of components fabricated with open-source 3-D printers under realistic environmental conditions. Mater. Des. 2014, 58, 242-246. [CrossRef]

26. Lužanin, O.; Movrin, D.; Plan, M. Effect of Layer Thickness, Deposition Angle, and Infill on Maximum Flexural Force in Fdm-Built Specimens. J. Technol. Plast. 2014, 39, 49-58. 
27. Tekinalp, H.L.; Kunc, V.; Velez-Garcia, G.M.; Duty, C.E.; Love, L.J.; Naskar, A.K.; Blue, C.A.; Ozcan, S. Highly oriented carbon fiber-polymer composites via additive manufacturing. Compos. Sci. Technol. 2014, 105, 144-150. [CrossRef]

28. Shofner, M.L.; Lozano, K.; Rodríguez-Macías, F.J.; Barrera, E.V. Nanofiber-reinforced polymers prepared by fused deposition modeling. J. Appl. Polym. Sci. 2003, 89, 3081-3090. [CrossRef]

29. Karsli, N.G.; Aytac, A. Tensile and thermomechanical properties of short carbon fiber reinforced polyamide 6 composites. Compos. Part B Eng. 2013, 51, 270-275. [CrossRef]

30. Love, L.J.; Kunc, V.; Rios, O.; Duty, C.E.; Elliott, A.M.; Post, B.K.; Smith, R.J.; Blue, C.A. The importance of carbon fiber to polymer additive manufacturing. J. Mater. Res. 2014, 29, 1893. [CrossRef]

31. Ning, F.; Cong, W.; Qiu, J.; Wei, J.; Wang, S. Additive manufacturing of carbon fiber reinforced thermoplastic composites using fused deposition modeling. Compos. Part B Eng. 2015, 80, 369-378. [CrossRef]

32. Ivey, M.; Melenka, G.W.; Carey, J.P.; Ayranci, C. Characterizing short-fiber-reinforced composites produced using additive manufacturing. Adv. Manuf. Polym. Compos. Sci. 2017, 3, 81-91. [CrossRef]

33. Papon, E.A.; Haque, A. Fracture toughness of additively manufactured carbon fiber reinforced composites. Addit. Manuf. 2019, 26, 41-52. [CrossRef]

34. Rao, V.D.P.; Rajiv, P.; Geethika, V.N. Effect of fused deposition modelling (FDM) process parameters on tensile strength of carbon fibre PLA. Mater. Today Proc. 2019, 18, 2012-2018.

35. Yasa, E. Anisotropic impact toughness of chopped carbon fiber reinforced nylon fabricated by material-extrusion-based additive manufacturing. Anadolu Univ. J. Sci. Technol. Appl. Sci. Eng. 2019, 20, 195-203.

36. Der Klift, F.; van Koga, Y.; Todoroki, A.; Ueda, M.; Hirano, Y.; Matsuzaki, R. 3D Printing of Continuous Carbon Fibre Reinforced Thermo-Plastic (CFRTP) Tensile Test Specimens. Open J. Compos. Mater. 2016, 6, 18. [CrossRef]

37. Melenka, G.W.; Cheung, B.K.O.; Schofield, J.S.; Dawson, M.R.; Carey, J.P. Evaluation and prediction of the tensile properties of continuous fiber-reinforced 3D printed structures. Compos. Struct. 2016, 153, 866-875. [CrossRef]

38. Dickson, A.N.; Barry, J.N.; McDonnell, K.A.; Dowling, D.P. Fabrication of continuous carbon, glass and Kevlar fibre reinforced polymer composites using additive manufacturing. Addit. Manuf. 2017, 16, 146-152. [CrossRef]

39. Tian, X.; Liu, T.; Yang, C.; Wang, Q.; Li, D. Interface and performance of 3D printed continuous carbon fiber reinforced PLA composites. Compos. Part A Appl. Sci. Manuf. 2016, 88, 198-205. [CrossRef]

40. McKeen, L.W. The Effect of Long Term Thermal Exposure on Plastics and Elastomers; William Andrew: Norwich, NY, USA, 2013; ISBN 9780323221085.

41. Fiber Force Italy. Available online: http://www.fiberforce.it/wp-content/uploads/2019/07/TDS_NY-CARBON_ REV-2.1.pdf (accessed on 23 August 2020).

42. Akhoundi, B.; Behravesh, A.H. Effect of Filling Pattern on the Tensile and Flexural Mechanical Properties of FDM 3D Printed Products. Exp. Mech. 2019, 59, 883-897. [CrossRef]

43. ASTM International. ISO/ASTM52900-15 Standard Terminology for Additive Manufacturing-General Principles-Terminology; ASTM International: West Conshohocken, PA, USA, 2015.

44. Rodríguez, J.F.; Thomas, J.P.; Renaud, J.E. Mechanical behavior of acrylonitrile butadiene styrene fused deposition materials modeling. Rapid Prototyp. J. 2003, 9, 219-230. [CrossRef]

45. Abeykoon, C.; Sri-Amphorn, P.; Fernando, A. Optimization of fused deposition modeling parameters for improved PLA and ABS 3D printed structures. Int. J. Light. Mater. Manuf. 2020, 3, 284-297. [CrossRef]

46. Fernandez-Vicente, M.; Calle, W.; Ferrandiz, S.; Conejero, A. Effect of Infill Parameters on Tensile Mechanical Behavior in Desktop 3D Printing. 3D Print. Addit. Manuf. 2016, 3, 183-192. [CrossRef]

47. Torrado, A.R.; Roberson, D.A. Failure Analysis and Anisotropy Evaluation of 3D-Printed Tensile Test Specimens of Different Geometries and Print Raster Patterns. J. Fail. Anal. Prev. 2016, 16, 154-164. [CrossRef]

48. Fused Deposition Modelling (FDM) Parts on Demand. Available online: https://www.stratasysdirect.com/ materials/fused-deposition-modeling (accessed on 20 September 2001).

49. Markforged, Material. Available online: https://markforged.com/materials/composites/ (accessed on 20 August 2020).

50. Products-Maker-Fiberforce. Available online: http://www.fiberforce.it/products-maker/ (accessed on 20 August 2020). 
51. Data Sheets Fillamentum. Available online: https:/fillamentum.com/pages/data-sheets (accessed on 22 August 2020).

52. García-Domínguez, A.; Claver, J.; Camacho, A.M.; Sebastián, M.A. Considerations on the applicability of test methods for mechanical characterization of materials manufactured by FDM. Materials. 2020, 13, 28. [CrossRef] [PubMed]

53. Friday, M.J. A comparison of tension test data using ASTM D 638 and ISO 527. In ASTM Limitations of Test Methods for Plastics; ASTM International: West Conshohocken, PA, USA, 1999.

54. Yasa, E.; Ersoy, K. Dimensional Accuracy and Mechanical Properties of Chopped Carbon Reinforced Polymers Produced by Material Extrusion Additive Manufacturing. Materials 2019, 12, 3885. [CrossRef]

(C) 2020 by the authors. Licensee MDPI, Basel, Switzerland. This article is an open access article distributed under the terms and conditions of the Creative Commons Attribution (CC BY) license (http://creativecommons.org/licenses/by/4.0/). 